\title{
LOOSENING OF THE POROUS COATING IN TOTAL KNEE REPLACEMENT
}

\author{
C. L. CHENG, A. E. GROSS
}

From the University of Toronta

\begin{abstract}
We reviewed 40 cementless Porous Coated Anatomic knee replacements in 34 consecutive patients. The average follow-up was 12.9 months (range 6 to 36 months). At review, loose beads were identified in 23 knees, in 11 on the femoral side and in 16 on the tibial side (in five knees on both sides). One loose bead was adjacent to the patella. In four knees there were intra-articular beads. Radiolucent lines at the interface between bone and prosthesis were seen in 19 knees, in six on the femoral side and in 16 on the tibial side (in three knees on both sides). In relation to the tibial component loose beads were associated with a radiolucent line in all except one case. Progressive loosening with an increasing number of loose beads was seen in three knees. At this early stage of follow-up there was no correlation between the clinical results and the presence of loose beads.
\end{abstract}

The use of the Porous Coated Anatomic (PCA) knee replacement without cement has been reported to give good or excellent early results in $90 \%$ of cases of osteoarthritis and rheumatoid arthritis (Hungerford and Kenna 1983). Few early failures or problems had been reported until evidence of loosening of the porous coating was published by Rosenqvist et al. (1986). We had observed in our series an association between a radiolucent line about the tibial component of the prosthesis and an appearance of loose beads. We have accordingly reviewed a consecutive series of cementless PCA knee replacements in an attempt to define the significance of these findings.

\section{MATERIALS AND METHODS}

Forty-three knees in 37 consecutive patients were replaced with a PCA prosthesis without cement from 1983 to 1986 at the Mount Sinai Hospital, Toronto. Three patients (three knees) were lost to follow-up but the remaining 40 knees in 34 patients were available for study; 14 were men and 20 were women. The average age at operation was 62.9 years (range 37 to 79 years). The diagnosis had been osteoarthritis in 34 knees and

C. L. Cheng, FRCS(G), FRACS, Senior Medical Officer Department of Orthopaedic Surgery, University of Hong Kong, Queen Mary Hospital, Hong Kong.

A. E. Gross, MD, FRCS(C), Professor and Head of Department Division of Orthopaedic Surgery, Department of Surgery, University of Toronto, Mount Sinai Hospital, 600 University Avenue, Toronto Ontario, M5G IX5 Canada.

Correspondence should be sent to $\mathrm{Dr} C$. L. Cheng, and requests for reprints to Professor A. E. Gross.

(C) 1988 British Editorial Society of Bone and Joint Surgery $0301-620 X / 88 / 3084 \$ 2.00$

J Bone Joint Surg [Br] 1988;70-B:377-81. rheumatoid arthritis in six. The average length of followup was 12.9 months (range 6 months to 36 months).

All the operations were done or supervised by the senior author (AEG). Prophylactic antibiotics, laminar flow and personal isolation systems were used in all cases. The special instruments designed for the PCA prosthesis were used and all components were uncemented. Cementless insertion was used only when bone quality was judged to be good. During operation, all components were tested for stability; this was achieved in all those which were left uncemented.

All tibial components had fixation pegs, and a cancellous screw was used for additional fixation of the tibial component in 18 knees, most in the early cases. Bone grafts were used to build up a deficient tibial plateau in four knees, but these were small and required no additional fixation. Patellar components were used in 15 knees.

Postoperatively, a compression bandage was used for two days and active mobilisation of the knee was started after suction drainage had been removed at 48 hours. Continuous passive motion was not used. The patients were non-weight-bearing on crutches for six weeks, then progressed gradually to full weight-bearing after another four to six weeks.

Radiographs of the knees were obtained soon after operation in the recovery room, at discharge from hospital after two or three weeks and then at half-yearly intervals. Anteroposterior, lateral and oblique views were taken with the $\mathrm{x}$-ray beams directed as nearly as possible in the plane of the joint. Radiolucent lines were measured on the best available radiographs. Beads were considered to be loose when they were totally separated from the surface of a prosthetic component on any one view, and were considered to be intra-articular when both anteroposterior and lateral radiographs showed 
Table I. Summary of clinical data of all cases

\begin{tabular}{|c|c|c|c|c|c|c|c|c|c|}
\hline \multirow[b]{2}{*}{ Case } & \multirow[b]{2}{*}{ Sex } & \multirow[b]{2}{*}{$\begin{array}{l}\text { Age } \\
\text { (years) }\end{array}$} & \multicolumn{2}{|c|}{ Femoral component } & \multirow[b]{2}{*}{$\begin{array}{l}\text { Intra-articular } \\
\text { beads }\end{array}$} & \multicolumn{2}{|c|}{ Tibial component } & \multirow[b]{2}{*}{$\begin{array}{l}\text { Follow-up } \\
\text { (months) }\end{array}$} & \multirow[b]{2}{*}{$\begin{array}{l}\text { Pain at } \\
\text { follow-up }\end{array}$} \\
\hline & & & $\begin{array}{l}\text { Radiolucent } \\
\text { line }(\mathrm{mm})\end{array}$ & Loose beads & & $\begin{array}{l}\text { Radiolucent } \\
\text { line }(\mathrm{mm})\end{array}$ & Loose beads & & \\
\hline 1 & $\mathbf{M}$ & 74 & 0 & 1 & 0 & 0 & 0 & 12 & No \\
\hline 2 & $\mathbf{M}$ & 74 & 0 & 0 & 0 & 0 & 0 & 12 & No \\
\hline 3 & $\mathbf{M}$ & 75 & $<1$ & 1 & 0 & 0 & 0 & 6 & No \\
\hline 4 & $\mathbf{M}$ & 75 & 0 & 0 & 0 & $<1$ & 2 & 6 & No \\
\hline 5 & $\mathbf{M}$ & 60 & 0 & 0 & 0 & 0 & 0 & 6 & Moderate \\
\hline 6 & $\mathbf{M}$ & 51 & 0 & 0 & 0 & 0 & 0 & 12 & No \\
\hline $7^{*}$ & $\mathbf{F}$ & 47 & $<1$ & 1 & 0 & 0 & 0 & 6 & No \\
\hline 8 & F & 63 & 0 & 1 & 0 & $<1$ & 1 & 24 & Mild \\
\hline 9 & $\mathbf{F}$ & 63 & 0 & 0 & 0 & 0 & 0 & 24 & No \\
\hline 10 & $\mathbf{M}$ & 56 & 0 & 1 & 0 & 0 & 0 & 6 & Moderate \\
\hline 11 & $\mathrm{~F}$ & 69 & 0 & 0 & 0 & $<1$ & 1 & 6 & Mild \\
\hline $12^{*}$ & $\mathbf{F}$ & 37 & 0 & 0 & 0 & 0 & 0 & 12 & Moderate \\
\hline $13^{*}$ & $\mathbf{F}$ & 37 & 0 & 0 & 0 & 0 & 0 & 12 & Moderate \\
\hline 14 & $\mathbf{F}$ & 61 & 0 & 0 & 0 & 0 & 0 & 6 & No \\
\hline 15 & $\mathbf{F}$ & 66 & 0 & 0 & 1 & 1 & 1 & 24 & No \\
\hline 16 & $\mathbf{F}$ & 70 & 0 & 1 & 0 & 1 & 2 & 12 & No \\
\hline 17 & $\mathbf{M}$ & 67 & 0 & 0 & 0 & $1-2 \dagger$ & 30 & 36 & No \\
\hline 18 & $\mathbf{M}$ & 67 & 0 & 0 & 0 & $<1$ & 3 & 24 & No \\
\hline 19 & $\mathbf{M}$ & 71 & 0 & 1 & 0 & $1 \dagger$ & 5 & 30 & Mild \\
\hline 20 & $\mathbf{F}$ & 64 & 0 & 0 & 0 & 0 & 0 & 6 & No \\
\hline 21 & $\mathbf{F}$ & 79 & 0 & 0 & 0 & 0 & 0 & 24 & No \\
\hline $22^{*}$ & $\mathbf{M}$ & 35 & $<1$ & 5 & 1 & $<1$ & 2 & 30 & No \\
\hline 23 & $\mathbf{M}$ & 69 & $<1$ & 1 & 0 & 0 & 0 & 6 & Mild \\
\hline 24 & $\mathrm{~F}$ & 65 & 0 & 1 & 0 & $1 \dagger$ & 1 & 6 & Severe \\
\hline 25 & $\mathrm{~F}$ & 63 & 0 & 0 & 0 & 1 & 2 & 12 & Mild \\
\hline 26 & $\mathbf{M}$ & 71 & 0 & 0 & 0 & $<1$ & 2 & 6 & Moderate \\
\hline $27^{*}$ & $\mathrm{~F}$ & 43 & 0 & 0 & 0 & 0 & 0 & 6 & No \\
\hline 28 & $\mathrm{~F}$ & 57 & 0 & 0 & 0 & 0 & 0 & 12 & No \\
\hline $29^{*}$ & $F$ & 60 & 0 & 0 & 0 & 0 & 0 & 6 & Mild \\
\hline 30 & $\mathrm{~F}$ & 76 & $<1$ & 0 & 0 & $<1$ & 2 & 6 & No \\
\hline 31 & $\mathbf{M}$ & 77 & 0 & 0 & 0 & 0 & 0 & 6 & Mild \\
\hline 32 & $F$ & 68 & 0 & 0 & 0 & 0 & 0 & 6 & No \\
\hline 33 & $\mathbf{M}$ & 65 & 0 & 0 & 0 & $1-2 \dagger$ & 21 & 24 & Severe \\
\hline 34 & $\mathbf{F}$ & 64 & 0 & 0 & 0 & $<1$ & 1 & 12 & No \\
\hline 35 & $\mathbf{M}$ & 75 & 0 & 0 & 4 & 0 & 0 & 18 & No \\
\hline 36 & $\mathbf{M}$ & 75 & $<1$ & 6 & 1 & $<1$ & 0 & 18 & No \\
\hline 37 & $\mathbf{F}$ & 57 & 0 & 0 & 0 & 0 & 0 & 12 & Moderate \\
\hline 38 & $\mathbf{F}$ & 63 & 0 & 0 & 0 & 0 & 0 & 6 & No \\
\hline 39 & $\mathbf{F}$ & 67 & 0 & 0 & 0 & 0 & 2 & 6 & Moderate \\
\hline 40 & $\mathbf{M}$ & 56 & 0 & 0 & 0 & 0 & 0 & 12 & No \\
\hline
\end{tabular}


them to be within the joint. The number of loose beads was counted as the maximum number shown on any one radiograph.

\section{RESULTS}

The detailed results are given in Table $I$.

Loose Beads. In the recovery room radiographs, loose beads were seen in five knees, three on the femoral side of the prosthesis, one on the tibial side and one apparently within the joint. In the most recent follow-up radiographs, loose beads were seen in 23 of the 40 knees. From one to six loose beads were seen on the femoral side in 11 knees (average number 1.8). From one to 30 loose beads were seen on the tibial side in 16 knees (average number 4.9). In five knees, loose beads were found on both the femoral and tibial sides, and in one knee a loose bead was seen in association with the patellar component.

Intra-articular beads were seen in four knees; four beads in one knee (Fig. 1) and one bead in each of the other three. Four beads of uncertain origin were seen in three knees. Of the 18 knees with cancellous screw fixation of the tibial component, eleven showed some loose beads.

Radiolucent lines. On the radiographs taken in the recovery room, incomplete radiolucent lines, all less than $1 \mathrm{~mm}$, were seen in six knees: three on the femoral side and three on the tibial side. At latest follow-up, incomplete radiolucent lines were present in six knees on the femoral side and all were less than $1 \mathrm{~mm}$ in width.

On the tibial side there were radiolucent lines in 16 knees; these were incomplete and of less than $1 \mathrm{~mm}$ in nine knees, $1 \mathrm{~mm}$ wide in five knees and between $1 \mathrm{~mm}$ and $2 \mathrm{~mm}$ in two knees. Of the seven radiolucent lines of $1 \mathrm{~mm}$ or more, four involved the whole tibial interface. Three knees showed radiolucent lines on both femoral and tibial sides, while only one patellar component had a radiolucent line which was $1 \mathrm{~mm}$ wide and complete.

Clinical Results. The clinical results were evaluated before and after operation using a 100-point scale (Table II) based on that reported by Hungerford and Kenna (1983). On this scale 90 or more points was an excellent result, 80 to 89 a good result, 70 to 79 a fair result. Under 70 points was a poor result. The average pre-operative score was 47 points (range 30 to 65 ), and the average postoperative score was 82.8 points (range 45 to 100). Twenty-one knees were rated excellent, ten knees were good, four were fair, and five knees were poor.

The five poor results were in four patients. In two knees the tibial components showed complete radiolucent lines and both patients had severe pain. Both replaced knees in a patient with rheumatoid arthritis recovered slowly with moderate pain and limited range of movement, probably due to the severity of her disease,

Table II. The 100-point rating system used for clinical evaluation after total knee arthroplasty (modified from Hungerford and Kenna 1983)

\begin{tabular}{|c|c|c|}
\hline \multirow[t]{5}{*}{ Pain } & No pain with any activity & 50 \\
\hline & $\begin{array}{l}\text { Performs most routine activities without pain, mild pain on excessive activity, } \\
\text { occasional mild analgesic or anti-inflammatory drugs }\end{array}$ & 40 \\
\hline & Moderate pain on routine activities, may require mild or narcotic analgesics & 25 \\
\hline & Severe pain on most activities, occasional rest pain, depends on cane or crutches & 10 \\
\hline & $\begin{array}{l}\text { Pain at rest frequently, cannot perform routine activities because of pain, walking } \\
\text { very difficult without supporting device }\end{array}$ & 0 \\
\hline \multirow[t]{4}{*}{ Stability } & (arc of abnormal medial or lateral movement in extended position) & \\
\hline & $0-5^{\circ}$ & 10 \\
\hline & $6^{\circ}-10^{\circ}$ & 5 \\
\hline & $>10^{\circ}$ & 0 \\
\hline \multirow[t]{7}{*}{ Deformity } & Varus/valgus $0-5^{\circ}$ & 10 \\
\hline & $6^{\circ}-10^{\circ}$ & 5 \\
\hline & $>10^{\circ}$ & 0 \\
\hline & Flexion contracture $<5^{\circ}$ & 0 \\
\hline & $6^{\circ}-10^{\circ}$ & -5 \\
\hline & $11^{\circ}-15^{\circ}$ & -10 \\
\hline & $>15^{\circ}$ & -15 \\
\hline \multirow[t]{5}{*}{ Mobility } & (total range of passive motion) & \\
\hline & $>120^{\circ}$ & 20 \\
\hline & $90^{\circ}-120^{\circ}$ & 15 \\
\hline & $45^{\circ}-89^{\circ}$ & 10 \\
\hline & $<45^{\circ}$ & 0 \\
\hline \multirow[t]{3}{*}{ Quadriceps } & Practically normal & 10 \\
\hline & Can be overcome by examiner & 5 \\
\hline & Against gravity only & 0 \\
\hline
\end{tabular}




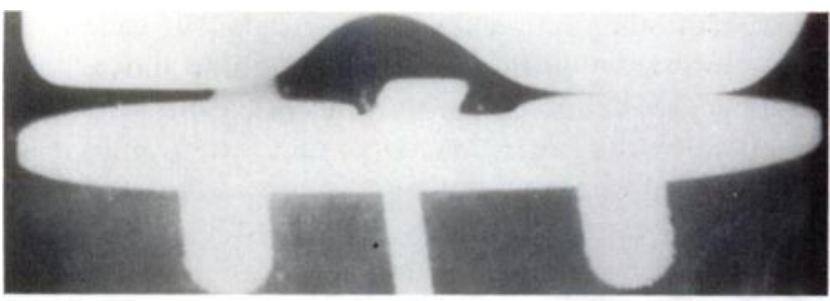

Fig. 1a

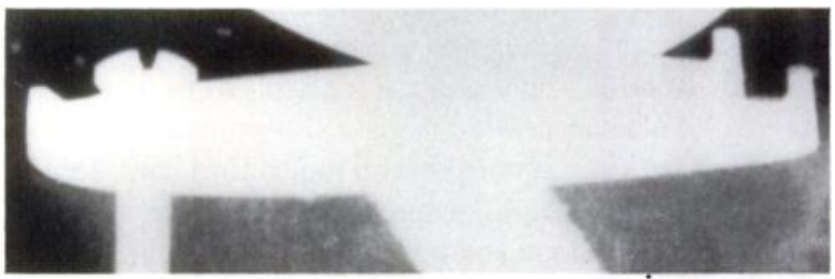

Fig. 1b

Anteroposterior and lateral radiographs showing a number of intraarticular beads.

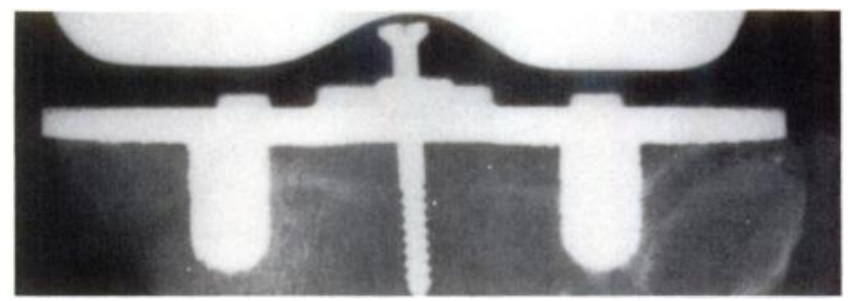

Fig. 2a

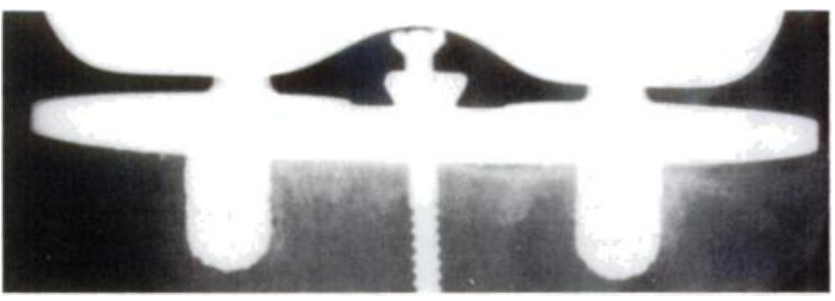

Fig. 2b

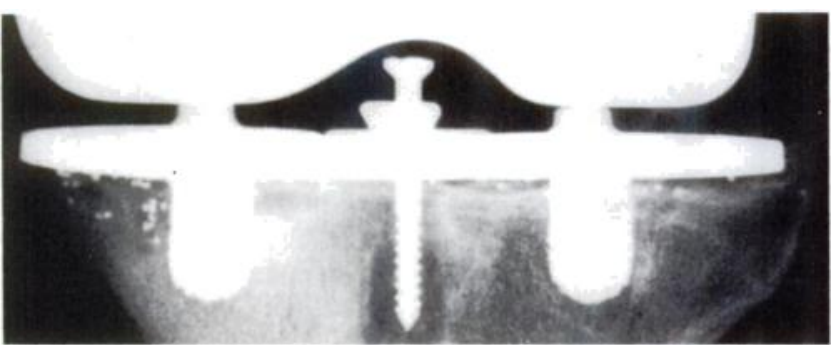

Fig. 2c

Radiographs showing progressive loosening and increasing numbers of loose beads. Figure $2 \mathrm{a}$ - Early postoperative film showing intimate contact between the tibial component and the bone. Figure $2 \mathrm{~b}-$ At six months showing an incomplete radiolucent line and a few loose beads. Figure 2c-At three years there is an increase in both the radiolucent zone and the number of loose beads. but radiographs showed neither radiolucent lines nor loose beads. The fifth poor result was in a patient with moderate pain, but no lucent line or loose beads. No definite cause could be found to account for the pain.

Correlations. No absolute correlation could be found between radiolucent lines and loose beads. In the recovery room radiographs, six knees showed radiolucent lines and five had loose beads, but in only two knees were they associated.

At latest follow-up, on the femoral side, 11 knees showed loose beads and only six showed radiolucent lines. Five knees showed both loose beads and radiolucent lines. On the tibial side, there was better correlation: $16 \mathrm{knees}$ had loose beads, 16 had radiolucent lines and in 15 of these the changes were present together. The single patellar component with a radiolucent line also showed one loose bead.

The three knees in our study with follow-up of over two years all had progressive loosening of the tibial component; this was associated with an increasing number of loose beads (Fig. 2). At six months follow-up there were two, three and five loose beads respectively; these increased to five, 30 and 21 by 24 to 36 months.

No correlation was found between the radiological findings of either radiolucent lines or loose beads and the clinical results. The average score at follow-up for the knees with radiolucent lines and loose beads was 82.7 (range 45 to 100), while the average score for the knees without radiolucent lines or loose beads was 82.8 (range 50 to 95$)$.

\section{DISCUSSION}

Uncemented porous-coated prostheses are intended to gain initial fixation by press fit, and long-term fixation by biological ingrowth (Hungerford, Kenna and Krachow 1982). The initial press fit, with intimate contact between prosthesis and bone, can only be achieved with considerable technical skill and accuracy, the use of the correct instruments and a properly designed prosthesis. The initial press fit must be maintained until ingrowth occurs (Cameron, Pilliar and Macnab 1973; Ducheyne et al. 1977). Bone ingrowth has been shown to take four to eight weeks in experimental animals (Cameron, Pilliar and Macnab 1976; Bobyn et al. 1980). The failure to obtain an initial press fit will lead to failure of bone ingrowth.

In our present series of 40 knees, radiolucent lines were present in almost half of the knees and this was closely associated with the presence of loose beads. These radiolucent lines indicate that bone ingrowth had not taken place, at least in that zone and probably elsewhere. Movement has been demonstrated between the tibial component and bone at such radiolucent interfaces (Green et al. 1983; Ryd 1986; Ryd et al. 1986). The presence of loose beads adjacent to a lucent line, neither of which was visible in radiographs taken in the recovery 
room, implies that movement at the interface has led to loosening of the porous coat. It is however possible that these early radiographs do not yield enough detail to diagnose all loose beads; theoretically the beads could be detached from the porous coat during insertion but not detected until later follow-up. We consider this to be unlikely because of the close association between loose beads that were diagnosed late and the presence of radiolucent lines. Moreover, three knees with follow-up of more than two years had progressive radiographic loosening with an increasing number of loose beads.

Various authors have reported a high incidence of radiolucency around the tibial component of total knee arthroplasty (Insall et al. 1976; Skolnick, Coventry and Ilstrup 1976; Reckling, Asher and Dillon 1977; Walker et al. 1981; Ryd 1986) and this is confirmed by our experience with cementless PCA prostheses. Most of the radiolucent lines and more loose beads occurred in relation to the tibial component, so it is likely that the fixation of this component either does not allow initial stability by press fit or that this stability is not maintained until bone ingrowth is complete, even after six weeks of non-weight-bearing. The use of a cancellous screw does not seem to give additional stability since we found no significant difference in the occurrence of loose beads between those with and those without a screw. Micromotion of the cementless PCA tibial implant with immediate weight-bearing has been demonstrated in all of the 13 cases reported by Ryd (1986).

Fixation of the femoral side does not seem to provide the same problem. Only six of our femoral components showed a radiolucent line, and all these were incomplete and less than $1 \mathrm{~mm}$ in width. The maximum number of loose beads was only six and in no case did we see progressive loosening or an increasing number of loose beads.

It has been shown that the presence of radiolucent lines in total knee arthroplasty does not necessarily imply clinical failure (Reckling et al. 1977; Vanhegan, Dabrowski and Arden 1979; Ryd 1986). At the present stage of follow-up the radiolucent lines and loose beads in our series do not correlate with the clinical results. However, beads in an intra-articular position must raise the possibility of increased wear of the polyethylene compo- nent. Our early clinical results with this cementless prosthesis have been favourable but our radiological findings give cause for concern because of the potential for polyethylene wear, ion release and increased symptoms. An effort should be made to strengthen the bond between the porous coat and the prosthesis.

No benefits in any form have been received or will be received from a commercial party related directly or indirectly to the subject of this article.

\section{REFERENCES}

Bobyn JD, Pilliar RM, Cameron HU, Weatherly GC. The optimum pore size for the fixation of porous-surfaced metal implants by the ingrowth of bone. Clin Orthop 1980;150:263-70.

Cameron HU, Pilliar RM, Macnab I. The rate of bone ingrowth into porous metal. J Biomed Mater Res 1976;10:295-302.

Cameron HU, Pilliar RM, Macnab I. The effect of movement on the bonding of porous metal to bone. J Biomed Mater Res 1973;7:301-11.

Ducheyne P, De Meester P, Aernoudt E. Influence of a functional dynamic loading on bone ingrowth into surface pores of orthopaedic implants. J Biomed Mater Res 1977;11:811-38.

Green DL, Bahniuk E, Liebelt RA, Fender E, Mirkov P. Biplane radiographic measurements of reversible displacement (including clinical loosening) and migration of total joint replacements. $J$ Bone Joint Surg [Am] 1983;65-A:1134-43.

Hungerford DS, Kenna RV. Preliminary experience with a total knee prosthesis with porous coating used without cement. Clin Orthop 1983;176:95-107.

Hungerford DS, Kenna RV, Krackow KA. The porous-coated anatomic total knee. Orthop Clin North Am 1982;13:103-22.

Insall JN, Ranawat CS, Aglietti P, Shine J. A comparison of four models of total knee-replacement prostheses. J Bone Joint Surg [Am] 1976;58-A :754-65.

Reckling FW, Asher MA, Dillon WL. A longitudinal study of the radiolucent line at the bone-cement interface following total jointreplacement procedures. J Bone Joint Surg [Am] 1977;59-A :355-8.

Rosenqvist R, Bylander B, Knutson K, et al. Loosening of the porous coating of bicompartmental prostheses in patients with rheumatoid arthritis. J Bone Joint Surg [Am] 1986;68-A:538-42.

Ryd L. Micromotion in knee arthroplasty: a roentgen stereophotogrammetric analysis of tibial component fixation. Acta Orthop Scand 1986;57 Suppl 220.

Ryd L, Lindstrand A, Rosenqvist R, Selvik G. Tibial component fixation in knee arthroplasty. Clin Orthop 1986;213:141-9.

Skolnick MD, Coventry MB, Ilstrup DM. Geometric total knee arthroplasty: a two-year follow-up study. J Bone Joint Surg [Am] 1976;58-A:749-53.

Vanhegan JAD, Dabrowski W, Arden GP. A review of 100 Attenborough stabilised gliding knee prostheses. $J$ Bone Joint Surg $[\mathrm{Br}]$ 1979;61-B:445-60.

Walker PS, Greene D, Reilly D, Thatcher J, Ben-dov M, Ewald FC. Fixation of tibial components of knee prostheses.J Bone Joint Surg [Am] $1981 ; 63-\mathrm{A}: 258-67$. 